\title{
Clinical characteristics of yamakagashi (Rhabdophis tigrinus) bites: a national survey in Japan, 2000-2013
}

Toru Hifumi ${ }^{1 *}$, Atsushi Sakai ${ }^{2}$, Akihiko Yamamoto ${ }^{3}$, Masahiro Murakawa ${ }^{4}$, Manabu Ato $^{5}$, Keigo Shibayama ${ }^{3}$, Akihiko Ginnaga ${ }^{6}$, Hiroshi Kato ${ }^{7}$, Yuichi Koido ${ }^{7}$, Junichi Inoue ${ }^{8}$, Yuko Abe ${ }^{1}$, Kenya Kawakita ${ }^{1}$, Masanobu Hagiike ${ }^{1}$ and Yasuhiro Kuroda ${ }^{1}$

\begin{abstract}
Background: Yamakagashi (Rhabdophis tigrinus) is a species of pit viper present throughout Russia and Eastern Asia. Although $R$. tigrinus venom is known to induce life-threatening hemorrhagic symptoms, the clinical characteristics and effective treatment of $R$. tigrinus bites remain unknown. The present study aimed to clarify these issues.

Methods: Records in the Japan Snake Institute between 2000 and 2013 were retrospectively investigated. The following were determined: patient characteristics, coagulation and fibrinolytic system abnormalities, effect of antivenom treatment, and outcomes.

Results: Nine patients (all males; median age, 38 years) with $R$. tigrinus bites were identified. On admission, the median levels of fibrinogen and fibrinogen degradation products, and platelet counts were $50 \mathrm{mg} / \mathrm{dL}$, $295 \mu \mathrm{g} / \mathrm{mL}$, and 107,000/ $\mathrm{mm}^{3}$, respectively. The median (minimum-maximum) disseminated intravascular coagulation (DIC) score defined by the Japanese Association of Acute Medicine was 8 (1-8). Antivenom was administered to seven patients, with a median interval of $35 \mathrm{~h}$ between bite and antivenom administration. All patients treated with antivenom survived, and the in-hospital mortality rate was $11 \%$.
\end{abstract}

Conclusions: Patients with $R$. tigrinus bites presented with DIC of a fibrinolytic phenotype, which can result in life-threatening injury unless appropriate antivenom and DIC treatment are provided.

Keywords: Yamakagashi, Rhabdophis tigrinus, Antivenom, Disseminated intravascular coagulation, Fibrinolytic phenotype

\section{Background}

Yamakagashi (Rhabdophis tigrinus) is a species of pit viper. It is present throughout Russia and Eastern Asia, including China, Taiwan, Korea, and Japan, but excluding Ryukyu Islands [1]. $R$. tigrinus venom is known to induce life-threatening hemorrhagic symptoms similar to those of the rattlesnake and other crotaline snakes [2-4]. However, the clinical characteristics and effective treatment of $R$. tigrinus bites remain unknown.

$R$. tigrinus antivenom was traditionally manufactured by the immunization of rabbits and goats. However,

\footnotetext{
* Correspondence: hifumitoru@gmail.com

'Emergency Medical Center, Kagawa University Hospital, Toru Hifumi; 1750-1 Ikenobe, Miki, Kita, Kagawa 761-0793, Japan

Full list of author information is available at the end of the article
}

because of low supply, manufacture has more recently been based on immunizing horses and is supported by Health Science Grants (1998-1999) from the Ministry of Health, Labour and Welfare in 2000 [1]. In addition, the management of $R$. tigrinus bites in intensive care has progressed dramatically in this century [5].

This study aimed to elucidate the clinical characteristics of $R$. tigrinus bites and to clarify the effectiveness of antivenom treatment.

\section{Methods}

The Japan Snake Institute records were retrospectively investigated for the period between January 1, 2000 and November 30, 2013. The study was approved by the institutional review board at the National Disaster Medical Center. 


\section{Diagnosis of $R$. tigrinus bites}

No definite diagnostic criteria exist. Diagnosis of $R$. tigrinus bites required lots of experience of clinical practice. Compared with Mamushi (Gloydius blomhoffii) bites, no apparent edema or pain is typically observed at the bite site [6]. However, $R$. tigrinus venom induces a fatal coagulopathy, which results in extensive hemorrhage [7]. Laboratory data usually show severe hypofibrinogenemia, which is considered both a sensitive and a specific diagnostic marker [6]. The disseminated intravascular coagulation (DIC) diagnostic criteria for critically ill patients were used, as outlined by the Japanese Association of Acute Medicine (JAAM criteria) [8]; DIC was defined as a total score of $\geq 4$.

\section{Treatment of $R$. tigrinus bites}

Fibrinogen levels $<100 \mathrm{mg} / \mathrm{dL}$ are considered appropriate for antivenom administration in clinical practice. The antivenom used against $R$. tigrinus bites was experimentally manufactured and was effective against bites by snakes belonging to the genus Rhabdophis [1]. In total, 1,369 vials were produced and stored at two institutes: the Japan Snake Institute (Gunma) and Kaketsuken (Kumamoto).

Severe adverse effects refer to anaphylactic shock in which the patient was at risk of death because of antivenom administration.

In clinical practice, physicians managing patients with snake bites usually ask for the assistance of the Japan Snake Institute, where diagnosis is confirmed according to laboratory data and clinical symptoms. Antivenom is then dispatched to the treating physician by police car throughout Japan, other than in the Kyusyu region. In the Kyusyu region, Kaketsuken supplies antivenom to the physicians in the presence of the patient. Antivenom is supplied only by these two institutes. Clinical data was routinely collected, and all cases of $R$. tigrinus bites were recorded in the Japan Snake Institute.

\section{Data collection}

The following parameters were recorded: age, gender, comorbidities, laboratory data, and DIC score, as well as treatment-related factors, including the adverse effects of antivenom, and the outcome at hospital discharge.

\section{Results}

Over the 14-year study period, nine patients were identified; the patient characteristics are summarized in Table 1 . The area where $R$. tigrinus bites were reported was limited to four regions: Kanto, Chubu, Shikoku, and Kyusyu (Figure 1). All nine patients were male, with a median age of 38 years (5-81).

On admission, the median levels of fibrinogen and fibrinogen degradation products (FDP) and platelet counts were $50 \mathrm{mg} / \mathrm{dL}, 295 \mu \mathrm{g} / \mathrm{mL}$, and $107,000 / \mathrm{mm}^{3}$, respectively. The median (minimum-maximum) DIC score was 8 (1-8) (Table 1). Antivenom was administered to seven patients, and the median interval between bite and antivenom administration was $35 \mathrm{~h}$; no apparent adverse effects were observed. DIC was treated using clotting factor replacement with fresh frozen plasma (FFP) and protease inhibitors in three patients (Table 2). All patients treated with antivenom survived. However, the in-hospital mortality rate was $11 \%$ for all patients because a patient who did not receive antivenom died.

Case 1 (a 54-year-old man) with severe liver cirrhosis survived without administering antivenom. He had been bitten on his right hand by $R$. tigrinus. Initially, he demonstrated decreased platelet counts and fibrinogen levels without increased FDP levels. He was closely followed up, and both platelet counts and fibrinogen levels were

Table 1 Characteristics of patients with Rhabdophis tigrinus bites and laboratory data on admission

\begin{tabular}{|c|c|c|c|c|c|c|c|c|c|c|}
\hline Case & Area & Age & Gender & Comorbidities & WBC $\left(/ \mathrm{mm}^{3}\right)$ & $\begin{array}{c}\text { Plt } \\
\left(\times 10^{4} / \mathrm{mm}^{3}\right)\end{array}$ & $\begin{array}{c}\text { Fibrinogen } \\
\text { (mg/dL) }\end{array}$ & PT-INR & $\begin{array}{c}\text { FDP } \\
(\mu \mathrm{g} / \mathrm{mL})\end{array}$ & DIC score \\
\hline 1 & Tokyo & 54 & $M$ & LC & 3,500 & 10.7 & 189 & 1.08 & 3.5 & 1 \\
\hline 2 & Fukuoka & 75 & M & $\mathrm{DM}, \mathrm{HT}$ & 17,300 & 1.8 & 50 & 2.62 & 271.5 & 8 \\
\hline 3 & Nagasaki & 38 & M & None & 10,000 & 12.5 & 34.8 & ODL & ODL & 3 \\
\hline 4 & Saga & 13 & M & None & 8,300 & 7.3 & 30 & ODL & 393 & 8 \\
\hline 5 & Fukuoka & 40 & M & None & 9,840 & 19.8 & 50 & 8 & 592 & 5 \\
\hline 6 & Aichi & 13 & M & None & 11,300 & 13.1 & 25 & 3.8 & 453 & 8 \\
\hline 7 & Gunma & 37 & M & None & 10,100 & 3.9 & 30 & 2.81 & 295 & 8 \\
\hline 8 & Saitama & 5 & M & MR & 25,800 & 22 & 50 & 7.46 & 209 & 5 \\
\hline 9 & Kochi & 81 & M & None & 6,330 & 7.2 & 50 & 2.71 & 262 & 8 \\
\hline Summary & & $38(5-81)$ & Male, 100\% & & $\begin{array}{c}10,000 \\
(3,500-25,800)\end{array}$ & $10.7(1.8-22)$ & $50(25-189)$ & 3.8 (1.08-ODL) & 295 (3.5-ODL) & $8(1-8)$ \\
\hline
\end{tabular}

Age, WBC, PIt, Fibrinogen, PT-INR, FDP, and DIC scores are expressed as median (minimum-maximum). WBC, white blood cell; PIt, platelet count; PT-INR, prothrombin time international ratio; FDP, fibrinogen degradation products; DIC, disseminated intravascular coagulation; ODL, over detection limit; LC, liver cirrhosis; DM, diabetes mellitus; $\mathrm{HT}$, hypertension. 


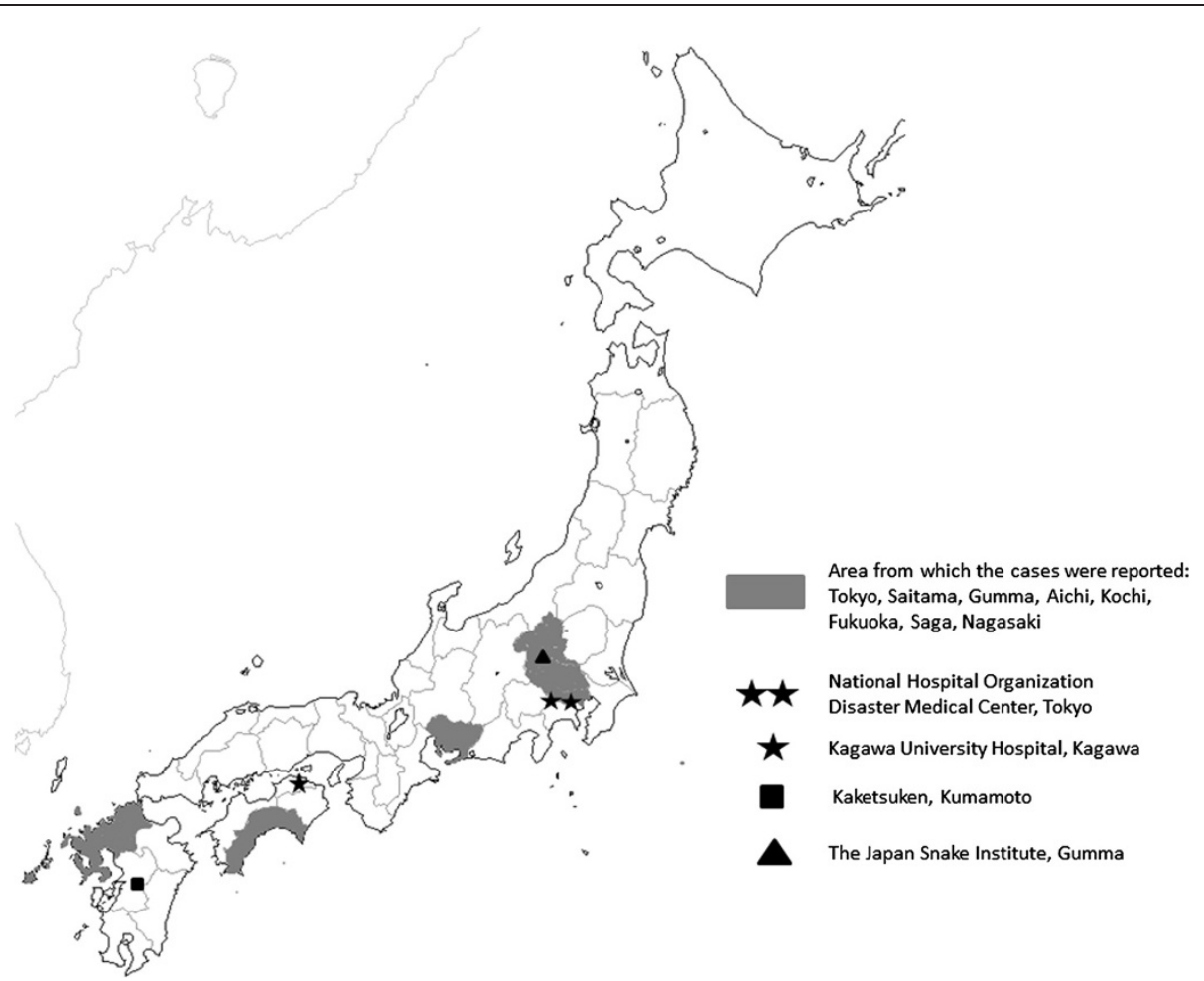

Figure 1 A map showing the relative locations of cases of Rhabdophis tigrinus bites. Tokyo, Saitama, Gunma, Aichi, Kochi, Fukuoka, Saga, and Nagasaki Prefectures.

not decreased on the second day of admission, which was considered to be caused by lower venom adsorption. Decreased platelet counts and fibrinogen levels on admission were caused by severe liver cirrhosis.

Case 2 (a 75-year-old man) died because of intracranial hemorrhage caused by DIC. He had been bitten on his left hand by a small snake and presented to the local clinic the next day with bleeding from the bite site. He was referred to the general hospital for further treatment and admitted without antivenom therapy. Two days after the bite, he developed disturbance of consciousness (Glasgow coma scale, 3) with 7-mm pupil dilation. Intracranial hemorrhage (bilateral acute epidural hemorrhage and subcortical hemorrhage) with cerebral herniation

Table 2 Treatment details and outcome

\begin{tabular}{|c|c|c|c|c|c|c|c|c|c|c|}
\hline Case & $\begin{array}{l}\text { Gabexate mesilate/ } \\
\text { nafamostat mesilate }\end{array}$ & FFP & $\mathrm{RCC}$ & $\begin{array}{l}\text { R. tigrinus } \\
\text { antivenom }\end{array}$ & $\begin{array}{c}\text { Time interval between } \\
\text { getting yamakagashi bites } \\
\text { and antivenom } \\
\text { administration (h) }\end{array}$ & $\begin{array}{l}\text { Adverse } \\
\text { effects } \\
\text { related with } \\
\text { antivenom }\end{array}$ & $\begin{array}{c}\text { Severe } \\
\text { adverse } \\
\text { effects }\end{array}$ & $\begin{array}{l}\text { ICU } \\
\text { days }\end{array}$ & $\begin{array}{l}\text { Hospital } \\
\text { days }\end{array}$ & Outcome \\
\hline 1 & No & No & No & No & & & & 2 & 2 & Survival \\
\hline 2 & No & Yes & Yes & No & & & & 6 & 6 & Dead \\
\hline 3 & No & No & No & Yes & 5.5 & No & No & 2 & 4 & Survival \\
\hline 4 & Yes & No & No & Yes & 24 & No & No & 0 & 6 & Survival \\
\hline 5 & No & No & No & Yes & 28 & No & No & 0 & 6 & Survival \\
\hline 6 & No & No & No & Yes & 35 & No & No & 0 & 7 & Survival \\
\hline 7 & No & No & No & Yes & 35 & No & No & 2 & 4 & Survival \\
\hline 8 & Yes & Yes & Yes & Yes & 60 & No & No & 0 & 14 & Survival \\
\hline 9 & Yes & Yes & No & Yes & 60 & No & No & 0 & 6 & Survival \\
\hline Summary & Yes, 33\% & $\begin{array}{l}\text { Yes, } \\
33 \%\end{array}$ & $\begin{array}{l}\text { Yes, } \\
22 \%\end{array}$ & Yes, 78\% & $35(5.5-60)$ & Yes, $0 \%$ & Yes, 0\% & $\begin{array}{c}0 \\
(0-6)\end{array}$ & $6(2-14)$ & $\begin{array}{c}\text { Survival, } \\
89 \%\end{array}$ \\
\hline
\end{tabular}

Data are expressed as median (minimum-maximum) for the length of time from Yamakagashi bite to antivenom administration, ICU days, and hospital days. FFP, fresh frozen plasma; RCC, red cell concrete. 
was revealed by computed tomography. Severe hypofibrinogenemia $(50 \mathrm{mg} / \mathrm{dL}$ ) also developed, and $R$. tigrinus was ultimately considered the definitive diagnosis. Antivenom was not administered at this late stage because of irreversible brain dysfunction. The patient died 8 days after the $R$. tigrinus bite.

\section{Discussion}

In the present study, we demonstrated the clinical characteristics of $R$. tigrinus bites that were effectively treated with antivenom administration and provided an outline of an untreated case. Compared with the incidence of Mamushi bites estimated, which is approximately 1,000 cases annually [9], the incidence of $R$. tigrinus bites is extremely rare; however, there is a possibility that mild cases without severe coagulopathy like case 1 were not reported and that some physicians may have diagnosed $R$. tigrinus bites as nonvenomous [1]. Case 2 presented in this report may serve as a reminder of the risks of such an approach and of the need for a high index of suspicion.

$R$. tigrinus venom shows strong plasma coagulant activity, with prothrombin activating effects and weak thrombin-like effects [10]. Once $R$. tigrinus venom is absorbed into the circulation, it activates prothrombin and thereby excessive coagulation. Disseminated fibrin formation ensues and fibrinolysis is activated, resulting in hypofibrinogenemia and increased FDP levels $[10,11]$. The current survey revealed that $R$. tigrinus bites caused severe DIC with a fibrinolytic phenotype. Based on the current data, it appears that following bites, $R$. tigrinus antivenom administration and appropriate DIC treatment can lead to complete recovery, even in the presence of severe DIC $[12,13]$.

Several days from $R$. tigrinus bites were required to administer antivenom in the present survey because of both the inconvenient supply of antivenom and the delays in diagnosis. Compared with the more common Mamushi bites, which are typically rapidly progressive, there appears to be a longer therapeutic window for administering $R$. tigrinus antivenom [14,15]. DIC with the fibrinolytic phenotype is usually not accompanied with multiple organ dysfunction, and hemorrhage is the major concern. The excessive fibrino/fibrinogenolysis without fibrin formation and life-threatening bleeding are contributed by the expression of tissue plasminogen activator (t-PA) [16,17]. Excess t-PA is secondarily induced by hypoperfusion in severe traumatic injury [16] and hypoxia $[18,19]$. $R$. tigrinus may therefore have neither a t-PA effect in itself [6] nor induce excessive t-PA. Indeed, patients in the present study did not develop severe hypoperfusion at any stage during hospitalization, including the period before the administration of $R$. tigrinus antivenom. Therefore, antivenom was considered effective beyond the initial acute phase. Further study is required to evaluate the indications and proper timing of antivenom administration on the basis of the mechanism described.

Adverse reactions to antivenom were negligible. Although the numbers in this survey are too low to make an assessment, the adverse reaction rate may be lower than the $2.4 \%-9 \%$ rate observed with Mamushi antivenom $[9,20]$. However, since both $R$. tigrinus and Mamushi antivenom are manufactured by immunizing horses, we should remain vigilant to the risk of adverse events such as anaphylaxis and serum sickness disease [21]. The great concern with current $R$. tigrinus bite treatment is that although the antivenom is effective, it is only experimentally manufactured by regional health laboratories [1]. Therefore, the sterility and safety are not guaranteed [1]. The Ministry of Health, Labour and Welfare of Japan has launched a research group to evaluate the safety and efficacy of antivenom and to organize and maintain information on $R$. tigrinus bites in 2013. Two hospitals have been selected as specialist centers for $R$. tigrinus bite treatment: The National Hospital Organization Disaster Medical Center, Tokyo and Kagawa University Hospital, Kagawa. Clinical characteristics and treatment details, including the adverse effects of antivenom, are recorded for all cases and analyzed to ensure proper safety. In addition, patients with $R$. tigrinus bites are covered by clinical research insurance to provide compensation in the event of adverse effects resulting from antivenom administration.

There are many limitations to this study. A major limitation is the fact that many cases remain undiagnosed or misdiagnosed because of the unfamiliar symptoms presented by this rare snakebite. In addition, we did not obtain specific clinical details, including coagulation markers, which would have been beneficial. Finally, as this was a retrospective analysis, the details of DIC were not obtained, such as the level of soluble fibrin and plasminogen activator inhibitor and treatment.

\section{Conclusions}

$R$. tigrinus bites are rare in clinical practice but demonstrated DIC with the fibrinolytic phenotype, which can result in life-threatening injury unless appropriate antivenom and DIC treatment are provided. Throughout the at-risk Asian countries, critical care physicians should be aware of this injury and its treatment.

\section{Competing interests}

The authors declare that they have no competing interests.

\section{Authors' contributions}

$\mathrm{TH}, \mathrm{AS}, \mathrm{AY}, \mathrm{YA}$, and $\mathrm{YK}$ collected the patient data. TH, MM, AG, HK, YK, J, YA, KK, and MH treated patients. TH wrote the manuscript. MA, KS, and YK revised and edited the manuscript. All authors read and approved the final manuscript. 


\section{Acknowledgments}

This study was supported by Health Science Grants (2013-2015) from the Ministry of Health, Labour and Welfare of Japan.

\section{Author details}

'Emergency Medical Center, Kagawa University Hospital, Toru Hifumi; 1750-1 Ikenobe, Miki, Kita, Kagawa 761-0793, Japan. ${ }^{2} J a p a n$ Snake Institute, 3318 Yabutsuka, Ota, Gunma 379-2301, Japan. ${ }^{3}$ Department of Bacteriology II, National Institute of Infectious Disease, Gakuen 4-7-1, Musashimurayama-shi, Tokyo 208-0011, Japan. ${ }^{4}$ Department of Internal Medicine, Kaizuka Hospital, Hakosaki 7-7-27 Higashi-kuFukuoka 812-0053, Japan. ${ }^{5}$ Department of Immunology, National Institute of Infectious Disease, Toyama 1-23-1, Shinjuku-ku, Tokyo 162-8640, Japan. ${ }^{6}$ The Chemo-Sero-Therapeutic Research Institute (KAKETSUKEN), 1-6-1 Okubo, Kita-ku, Kumamoto-shi, Kumamoto 860-8568, Japan. 'Division of Critical Care Medicine and Trauma, National Hospital Organization Disaster Medical Center, 3256 Midori-cho, Tachikawa, Tokyo 190-0014, Japan. ${ }^{8}$ Division of Critical Care Medicine and Trauma, Yamanashi Prefectural Central Hospital, 1-1-1 Fujimi, Kofu, Yamanashi 400-8506, Japan.

\section{Received: 21 December 2013 Accepted: 21 February 2014}

Published: 6 March 2014

\section{References}

1. Morokuma K, Kobori N, Fukuda T, Uchida T, Sakai A, Toriba M, Ohkuma K, Nakai K, Kurata T, Takahashi M: Experimental manufacture of equine antivenom against yamakagashi (Rhabdophis tigrinus). Jpn J Infect Dis 2011, 64:397-402.

2. Mori K, Hisa S, Suzuki S, Sugai K, Sakai H, Kikuchi T, Hiwatashi N, Shishido H, Goto Y, Takahashi T: A case of severe defibrination syndrome due to snake (Rhabdophis tigrinus) bite. Rinsho ketsueki 1983, 24:256-262.

3. Tanen D, Ruha A, Graeme K, Curry S: Epidemiology and hospital course of rattlesnake envenomations cared for at a tertiary referral center in Central Arizona. Acad Emerg Med 2001, 8:177-182.

4. Boyer LV, Seifert SA, Clark RF, McNally JT, Williams SR, Nordt SP, Walter FG, Dart RC: Recurrent and persistent coagulopathy following pit viper envenomation. Arch Internal Med 1999, 159:706-710.

5. Dellinger RP, Carlet JM, Masur H, Gerlach H, Calandra T, Cohen J, Gea-Banacloche J, Keh D, Marshall JC, Parker MM, Ramsay G, Zimmerman JL, Vincent JL, Levy MM, Surviving Sepsis Campaign Management Guidelines Committee: Surviving Sepsis Campaign guidelines for management of severe sepsis and septic shock. Crit Care Med 2004, 32:858-873.

6. Sakai A: Clinical feature of envenomation by the snake, Yamakagashi (Rhabdophis tigrinus). Chudoku kenkyu 2007, 20:235-243.

7. Sakai AHM, Sawai Y: Study on the pathogenesis of envenomation by the Japanese colubrid snake, Yamakagashi, Rhabdophis tigrinus. Snake 1990, 22:11-19.

8. Gando S, Iba T, Eguchi Y, Ohtomo Y, Okamoto K, Koseki K, Mayumi T, Murata A, Ikeda T, Ishikura H, Ueyama M, Ogura H, Kushimoto S, Saitoh D, Endo S, Shimazaki S, Japanese Association for Acute Medicine Disseminated Intravascular Coagulation (JAAM DIC) Study Group: A multicenter, prospective validation of disseminated intravascular coagulation diagnostic criteria for critically ill patients: comparing current criteria. Crit Care Med 2006, 34:625-631.

9. Hifumi T, Yamamoto A, Morokuma K, Ogasawara T, Kiriu N, Hasegawa E, Inoue J, Kato H, Koido Y, Takahashi M: Surveillance of the clinical use of mamushi (Gloydius blomhoffii) antivenom in tertiary care centers in Japan. Jpn J Infectious Dis 2011, 64:373-376.

10. Komori K, Konishi M, Maruta Y, Toriba M, Sakai A, Matsuda A, Hori T, Nakatani M, Minamino N, Akizawa T: Characterization of a novel metalloproteinase in Duvernoy's gland of Rhabdophis tigrinus tigrinus. J Ttoxicoll Sci 2006, 31:157-168.

11. Gando S: Acute coagulopathy of trauma shock and coagulopathy of trauma: a rebuttal. You are now going down the wrong path. J Trauma 2009, 67:381-383.

12. Kato MTS, Kiyohara Y: A case of Yamakagashi (Rhabdophis tigrinus) bite. Rinsho Derma 2003, 45:133-136.

13. Brown SG, Caruso N, Borland ML, McCoubrie DL, Celenza A, Isbister GK: Clotting factor replacement and recovery from snake venom-induced consumptive coagulopathy. Intensive Care Med 2009, 35:1532-1538.
14. Fujita MYS, Kawamura Y, Tsuruta R, Kasaoka S, Okabayashi K, Maekawa T: Viper (agkistrodon halys blomhoffii "Mamushi") bite with remarkable thrombocytopenia. JJAAM 2005, 16:126-130.

15. Nakamura KIN, Murakami M, Ogawa Y, Momii S: A case of acute renal and respiratory failure due to mamushi bite. JJAAM 2010, 21:843-848.

16. Sawamura A, Hayakawa M, Gando S, Kubota N, Sugano M, Wada T, Katabami K: Disseminated intravascular coagulation with a fibrinolytic phenotype at an early phase of trauma predicts mortality. Thrombosis Res 2009, 124:608-613.

17. Mangum M, Venable RH, Boatwright JD, Cocke TB: Hypoxia: a stimulus for tissue plasminogen activator release in humans? Aviat Space Environ Med 1987, 58:1093-1096.

18. Bartsch P, Haeberli A, Hauser K, Gubser A, Straub PW: Fibrinogenolysis in the absence of fibrin formation in severe hypobaric hypoxia. Aviat Space Environ Med 1988, 59:428-432.

19. O'Brodovich HM, Andrew M, Gray GW, Coates G: Hypoxia alters blood coagulation during acute decompression in humans. J Appl Rhysiol Respir Environ Exerc Physiol 1984, 56:666-670

20. Hifumi T, Yamamoto A, Morokuma K, Okada I, Kiriu N, Ogasawara T, Hasegawa E, Kato H, Inoue J, Koido Y, Takahashi M: Clinical efficacy of antivenom and cepharanthine for the treatment of Mamushi (Gloydius blomhoffii) bites in tertiary care centers in Japan. Jpn J Infect Dis 2013, 66:26-31.

21. Dart RC, McNally J: Efficacy, safety, and use of snake antivenoms in the United States. Ann Emerg Med 2001, 37:181-188.

22. General overview of research projects.

doi:10.1186/2052-0492-2-19

Cite this article as: Hifumi et al:: Clinical characteristics of yamakagashi (Rhabdophis tigrinus) bites: a national survey in Japan, 2000-2013. Journal of Intensive Care 2014 2:19.

\section{Submit your next manuscript to BioMed Central and take full advantage of:}

- Convenient online submission

- Thorough peer review

- No space constraints or color figure charges

- Immediate publication on acceptance

- Inclusion in PubMed, CAS, Scopus and Google Scholar

- Research which is freely available for redistribution

Submit your manuscript at www.biomedcentral.com/submit
C BioMed Central 